\title{
Clinical implications of phage display technique: Digging deeper in diagnostic and therapeutic grounds.
}

\author{
Huda Rajani ${ }^{1}$, Fatima Alshaikh ${ }^{1}$, and Reza Maleki ${ }^{2}$ \\ ${ }^{1}$ Tehran University of Medical Sciences \\ ${ }^{2}$ Shahid Beheshti University of Medical Sciences
}

May 5, 2020

\begin{abstract}
Phage display is considered as a gold-standard technique for the extraction of monoclonal antibodies. Within the past decade, the technique has been extensively applied in clinical studies for the discovery of peptides, ligands and antibodies that can be implemented for the detection of clinical biomarkers and therapeutic purposes. This review highlights recent advancements in the field of phage display technology that has aided medicine in therapeutic and diagnostic terms.
\end{abstract}

\section{Introduction}

Phage display technology was first introduced by George P. Smith, who integrated protein coding fragments into filamentous bacteriophage M13 and the process of selection of desired protein fragment was named as panning [1].

Phage display is an inexpensive technology exploited for exogenous peptides, aiding increased target affinity and interaction [2]. It integrates the principles of genetic engineering with combinatorial chemistry. In general, phage display is composed of a system where exogenous DNA is interested in a filamentous phage genome along with the phage coat encoding sequence. Expression leads to the phage particles that express the sequence of interest in fusion with on the coat protein. These sequences are capable of interacting with various external targets/ligands. One of the significant characteristics of phage display is the production of large number of libraries and hence, these libraries can be used for the determination of the functional peptides with desired properties [3]. Proteins, peptides and antigens depend on the conformational changes to attain complete structural and functional characteristics. Immunization methods are barrier to this whereas, phage display method can be used to determine peptides and antigens for several ranges of epitopes and peptides [1].

M13 bacteriophage is the most commonly used phages for the purpose, owing to its flexible cylindrical protein structure and a large number of coat proteins including pIII, pVI, pVIII,pVII and pIX. pIII coat protein is responsible for the attachment of the bacteriophage virus to the pilus of the bacteria. After the attachment of pIII to the membrane protein, the genome of the phage is transferred into the bacteria where it is converted into a double stranded DNA and synthesis of new proteins occur around single stranded phage genome. The final phage particles are extruded from the bacteria, however, M13 phages do not kill the bacteria and remain in the constant phase of infection and growth [4]. The basic process of phage display is summarized in figure 1.

1.1 Natural and synthetic peptide library:

In term of peptides, phage libraries are either composed of natural peptides or synthetic ones. Natural peptide libraries are constructed by extracting DNA fragments from the organism (example: mice) and 
inserting it into the phage particle. As a result, phage particles, on their surface, express natural peptides. However, synthetic libraries are composed of cloned synthetic and randomly generated oligomeric sequences inserted into the phage genome [4].

\subsection{Antibodies-based libraries}

Several small antibody fragments such as; $\mathrm{scFv}$ (variable light and heavy chain fragments joined by polypeptide linker), Fab (antigen binding region) have been used to prepare phage libraries. These antibody-based libraries are widely used for epitope mapping, by biopanning of the antigen or the whole cell [5]. These libraries can naive that is, they are generated by extracting antibodies antigen-immunized animals. Whereas, nonimmunized libraries are constructed by rearrangement of antibody fragment, extracted from the healthy B cells. The process is achieved by the means soeing PCR (polymerase chain reaction) [4].

\subsection{Biopanning}

Following the amplification and infection of the bacteriophage viruses in the bacteria, the obtained phages are used for the biopanning process. The process involves introduction of the libraries to the target (cell, antigen, receptor or other proteins) bound onto the solid surface. Unbound phages are washed and removed whereas, bound ones are eluted, and the results are analyzed by the means ELISA (enzyme linked immunosorbent assay). In order to obtained high affinity and specific phages, $4-5$ rounds of panning are performed using the phages obtained from the preceding rounds [6].

This review is designed to highlight some of the significant applications of phage display in the field of medical sciences, implemented as a tool for diagnostic and therapeutic medicine.

\section{Alzheimer's disease}

Alzheimer's disease (AD) is a neurodegenerative disease characterized by dementia and is a significant cause of disability and socioeconomic burden. Aggregation of extracellular deposits of amyloid-beta (A $\beta$ ) peptides composed of tau protein forming mesh-like plaques and intracellular neurofibrillary tangles are known pathological mechanisms of AD. Most of the currently available drugs are targeted at the late stage of the disease and contribute minimally to the cure of the disease [7]. In earlier studies, mirror phage display had been exploited to extract D3 enantiomer from 9-mer peptide library that was able to reduce plaque formation in rats' brain [8].

Dammers, et al. [9] discovered a D-enantiomer peptide that binds to the parried helical fragment 6 (PHF6) of the tau protein and regulates the aggregation of the protein. They concluded that, owning to the cellpenetrating abilities, stability and low immunogenicity of this peptide, it can be further studied for the treatment and diagnosis of AD. Using mirror phage display, Rudolph, et al. [10] reported Mosd1 (monomer specific d-peptide 1) peptide that could degrade $A \beta_{1-42}$ and reduce the corresponding toxicity in ex-vivo studies. Also, in a recent findings, $\beta$-secretase (BACE1) peptide, using phage display, has been identified that could bind to BACE1 and reduce the production of $A \beta$ plaques [11]. Similar techniques have been exploited for the generation of peptides against receptor for advanced glycation end product (RAGE) that decreases $\mathrm{A} \beta$-associated cellular degradation, simply by down-regulating apoptosis, reducing oxidative stress and BACE1 responses [12].

The engineering of Anticalins, as $A \beta$ neutralizing agents from human lipocalin has also been achieved using similar techniques, where the peptides were reported to reduce the $A \beta$ aggregation [13].

Munke, et al. [14]developed a strategy to inhibit the fibril-dependent nucleation of $\mathrm{A} \beta$ peptide, in order to repress the process of aggregation. Using phage display technique, they achieved scFv fragments from three rounds of biopanning against A $\beta 42$ fibrils. These antibodies had potency to inhibit secondary nucleation due to their increased specificity towards the $A \beta$ fibrils, thereby suppressing aggregation. Moreover, in a recent clinical study [15], peptides from AD patients and controls were selected using phage display. These peptides have been reported to detect AD inflammation-associated cytokines and have a potential to be used as a biomarker for the diagnosis. Furthermore, high throughput-screening has allowed the diagnosis of 
$\mathrm{AD}$ autoantibodies using $\mathrm{T} 7$ phage libraries enabling the detection of blood-based markers in the sera and cerebrospinal fluid [16]. A recent study identified that peptides such as Anthrax toxin receptor 1, Nuclear protein 1, Glycogen phosphorylase, and Olfactory receptor 8J1 can be exploited for the diagnosis of AD, where T7 phage library can used for the identification of these peptides from AD samples [17].

Similarly, a cyclic peptide DAG, identified from phage display, binds to the different peptides in mice models that marks the upregulation of pathologic molecules such as, connective tissue growth factor in AD models [18]. To it, tau antibodies have also been identified in AD patients using phage display and hybridoma techniques [19].

\section{Diabetes Mellitus (DM)}

Of 422 million people with diabetes, $90 \%$ of them suffer from type 2 diabetes (T2D) [20]. Type 1 diabetes (T1D) is an autoimmune disease characterized by the destruction of pancreatic beta islets, disabling the secretion of insulin. In both the cases, DM is characterized by hyperglycemic conditions, increased oxidative stress and apoptosis of beta cells. Furthermore, systemic effects such as; nephropathy, cardiomyopathies, of both the types are nearly similar [21]. For which, diabetes- associated thrombotic risk was studied and phage display-based therapeutic approach has been exploited [22]. Additionally, diabetes-associated molecules such as; Glucose transporter type 4 (regulated by insulin) are also studied and analyzed using the technique [23].

$\alpha$-amylase converts starch into the simple sugars and owing to the low levels of insulin in diabetic patients, this is not considered to be a favorable condition. Therefore, several approaches have been designed to produce $\alpha$-amylase inhibitor, as a therapeutic measure in diabetic patients. Ngoh, et al. [24] used phage display to screen novel anti- $\alpha$-amylase from pinto beans. They reported SyP9 clone with the greatest inhibitory activity where, tyrosine, leucine, methionine, aspartic acid, alanine and histidine of $\alpha$-amylase showed strongest affinity towards the peptide.

Chimeric antigen receptors (CARs) along with T regulatory cells have been therapeutically targeted towards the antigen of interest. Insulin-specific CARs and scFvs, generated using phage display have been recently reported by Tenspolde, et al. [25]. scFv HAL9 and HAL10 phage libraries were used to extract insulinspecific phages. These were then, used to generate insulin-specific CARs by using retroviral CAR vector containing T-cell activation and co-stimulation domains (CD28) and Foxp3, as illustrated in figure 2. These insulin-specific CAR converted Treg cells showed high affinity towards insulin, and the technique was able to change the specificity of $\mathrm{T}$ cells.

Exenatide is widely used for the treatment of type II diabetes however, it is known to have a very short half-life. In a study, a phage display method was used to extract human serum albumin binding peptide, aptide. It was reported that this peptide has high affinity for exenatide and increases the half-life of the drug by 4 -folds. Furthermore, improved glucose tolerance was also seen [26]. Demartis, et al. [27] extracted the peptides using phage display libraries that were agonist for glucagon and glucagon like receptors, suggesting that these peptides can be used for antidiabetic and antiobesity studies, due to the role of these receptors in the following disorders.

Zinc transporter protein 8 ( $\mathrm{ZnT} 8$ ) is secreted by pancreatic beta islets and autoantibodies of this proteins have been recently studied as type 1 diabetes marker [28]. Using scFv phage display library, ZnT8-specific antibodies have been extracted which had great specificity for beta cells, having immunodiagnostic applications [29].

PACAP (pituitary adenylate cyclase activating polypeptide) is a neuropeptide that is known for its protective effects in various pathologies including diabetes [30]. A 31-mer PACAP-derived peptide constituting of a 7 mer albumin biding peptide, factor Xa and dipeptidyl peptidase IV cleavage peptide enable increased section of insulin and alleviation of blood glucose levels by binding specifically to VPAC2 (Vasoactive intestinal peptide receptor 2 ) [31]. Urinary and plasma L-Carnitine reduction is seen in T2D cases in some studies [32]. Using Tomlinson I and J scFv library, Abou El-Magd, et al. [33] identified a novel antibody fragment 
that could be used a diagnostic tool for the measurement of L-carnitine levels, owing to its specific Lcarnitine-like binding abilities.

\section{Gastrointestinal disorders}

In a recent study, scFv phage library was used for the extraction of antibodies against vacuolating cytotoxin A (VacA) toxins from $h$. pylori (helicobacter pylori). The complementarity determining regions (CDR) of these antibodies showed high affinity against VacA toxin, indicating its application as diagnostic tool [34]. Similarly, a recent study has reported ArsS antagonistic peptides that are capable of blocking acid-sensing signals, ultimately, providing a challenging environment for the growth of $h$. pylori [35]. Facchin, et al. [36] extracted peptides from ulcerative colitis and Crohn's disease patients which were integrated into virusmimicking nanoassemblies, composed of 400 peptides per nanoparticle. Next, the colorimetric assay and immunofluorescent staining were used to distinguish between ulcerative colitis and Crohn's disease samples.

Furthermore, Cardona-Correa and Rios-Velazquez [37] used 7-mer phage library for the detection of peptides involved in the pathogenesis of Bacillus anthracis toxin, lethal factor.

\section{Cardiovascular diseases}

Several biomarkers are now discovered for early identification of cardiovascular diseases. Phage display technique is widely studied in this respect. Park, et al. [38] identified 12-mer peptide specific for rat troponin I that had the potential of early detection of acute myocardial infraction. Similarly, scFv library ETH-2Gold was used for the discovery secretome-specific antibody against junction plakoglobin in atherosclerosis plaques, thrombi of acute coronary syndrome and peripheral monocytes and macrophages [39]. In a recent study by Hemadou, et al. [40], in-vivo phage display using scFv library has been performed for the extraction of atherosclerosis-specific antibodies. In this study, phages were injected into the atherosclerotic region in the rabbit and in-vivo biopanning of aorta was performed. Next, flow cytometric analysis was conducted on these eluted phages against atherosclerotic proteins such as; apolipoprotein, enolase 2, fatty acid-binding protein 7, matrix metalloproteinase 2, plasminogen and Acyl-coenzyme A oxidase 1 (to name few). A recent study has also proposed for the detection of galectin 3 in atherosclerosis plaques in preclinical and human-based models [41].

Kawasaki disease, presented by the inflammation of medium-sized vessels that leads to several other cardiovascular disorders, has also been studied in this aspect. In a recent clinical study, sera of patients with known viral cause were screened using phage display to compare with the ones with unknown etiology. However, owing to the complicated nature of the infection, unique information was very scarce in this study [42].

Furthermore, high-density lipoprotein (HDL) from coronary artery disease patients have also been used for biopanning to obtain anti-HDL antibodies. These antibodies were capable of binding with apolipoproteins A-1 and 2, illustrating the diagnostic application of the technique [43].

\section{Cancer}

Several peptides have been identified to for the diagnosis and treatment of cancer. These are capable of targeting tumor microenvironment including immune cells, cancer fibroblasts, extracellular matrix, tumor vasculature and tumor endothelial cells [44]. Cyclic phage libraries are also used for the discovery of antitumorigenic cyclic peptides like beta-catenin, $\gamma$-melanocyte-stimulating hormone and ligands for notch 1 receptor [45]. Claudins are transmembrane proteins that are over-expressed in cancerous cells. A recent study reported a discovery of IgG1 monoclonal antibody h4G3 that showed cytotoxic effects in claudin 3 expressing tumors [46]. A phase I clinical trial including 6 patients in the IV stage of the cancer was conducted by Shukla, et al. [47]. In this study, soluble scFv phage library was administered to the patients and the tumor was surgically resected. The antibody fragments showed great specificity towards the tumor cells, where one of the clones was similar to IL17A. The results of the study concluded the safety and specificity of the method in human subjects. Furthermore, phage display-extracted peptides are also used for the detection of cancer cells in biopsies samples [48]. 
6.1 Thyroid Cancer: Carneiro, et al. [49] reported a peptide using scFv phage library that had affinity to bind to papillary thyroid carcinoma proteins, OTU domain-containing protein 1, particularly those presented in stage I and II of the tumor. To it, monoclonal 131I-scFv antibody, designed by the amplification of VL and $\mathrm{VH}$ genes, has also been reported for the detection of medullary thyroid carcinoma using radiolabeled imaging methods. The authors concluded that this molecular probe is effective for the diagnosis of tumor angiogenesis [50].

6.2 Prostate Cancer: Prostate-specific membrane antigen (PSMA) that is over-expressed in prostate cancer and is a known biomarker, that showed specific binding with GT1 peptide, obtained from the rounds of biopanning on PSMA-positive LNCaP cells. This peptide can also deliver proapoptotic peptide to the cells, hence inducing cell death. These applications have allowed researchers to investigate the phage display technique for the delivery of the drugs within the specific cells [51]. Ph.D.-C7C, a library of random peptides containing disulfide constrained loops, has also been exploited for the detection of prostate cancer. Wada, et al. [52] reported that LN1 peptide binds specifically to prostate cancer cells and when bound to apoptotic peptide (KLA peptide) can induce the inhibition of the proliferation of cells.

6.3 Leukemia : Whole cell biopanning with acute myeloid leukemia M2-derived Kasumi-1 cell for specific $\mathrm{scFv}$ fragments was performed by Fitting, et al. [53]. They reported that these fragments, when fused with Pseudomonas exotoxin A, can induce cell apoptosis.

Adult T-cell leukemia (ALT), caused by T-cell leukemia virus type I, expresses sugar chain that are likely to be specific for the diseased state. Using fiber-type Sugar Chip (fiSC) that could enables the interaction of sugar binding proteins with sugar chains, Muchima, et al. [54] screened scFv fragments that could bind to ALT cell surface sugar chain, O-glycan, illustrated in figure. The study reported the extraction of two highly sulfated disaccharide structures having high affinity for ALT where, non-ALT cells were used as the control. Similarly, 9mer M13 phage library labelled with fluorescein isothiocyanate (FITC) was used for the detection of chronic lymphocytic leukemia (CLL). The researchers designed a single drop biosensor based on labelled phage probes for the detection of CLL peripheral blood mononuclear cells [55]. Antibodies against CD32, CD200, and HLA-DR (human leukocyte antigen-DR) on CLL cells, screened using phage display have shown great potency for the treatment of the disease as compared to the already existing CD20-specific monoclonal antibody, rituximab. These antibodies are currently in phase I and Phase II of the clinical trials. [56]

6.4 Breast cancer: A number of studies have reported the diagnostic and therapeutic applications of phage display technique for breast cancer. The tumors are known to present a great level of heterogeneity that has challenged an early diagnosis and the treatment of the cancer. Antibodies and peptides against CD271+ [57], Mrps18a [58], neuropilin-1, platelet-derived growth factor and human epidermal growth factor receptor 2 have been identified using this technique [59]. To it, cell biopanning has also been studied in this aspect [60-62]

6.5 Colon cancer: Hou, et al. [63] reported peptide CBP-DWS, using phage display, that had an ability to bind to colon cancer cells. Bioinformatic analysis showed that this peptide binds to glypican-3 on the colon cancer cells. A recent study, conducted by Ferreira, et al. [64] Biopanning and Rapid Analysis of Selective Interactive Ligands (BRASIL) was used to obtain a peptide, RKOpep, by biopanning on RKO cell line that could target monocarboxylate transporter 1 on the cell surface.

A proliferation-inducing ligand (APRIL) peptide, that is predominantly expressed in tumor tissues and is responsible for the growth and metastasis of the tumors along with the drug resistance, was targeted for colon cancer therapy in mouse model. The study reported that phage clones bind to these peptides on LOVO cells and inhibit the progression of cell cycle and proliferation, thereby inducing apoptosis [65]. Similar methods have been applied for the diagnosis of gastric cancer [66], colorectal cancer [67], esophageal cancer [68], urinary bladder cancer [69] and hepatocellular carcinoma [70]. Wang, et al. [71] reported P4 peptide extracted using 7-mer phage library, that shared homology with domain II-III of fibroblast growth factor-9 (FGF9) high affinity receptor. P4 showed tight binding with FGF9 and suppressed cell proliferation. Furthermore, in chemotherapy resistant tumor cells, mediated by the action of FGF9, P4 is hypothesized to 
have therapeutic potential.

6.6 Ovarian and cervical cancer: Phage display method has been used for the identification of ovarian cancerspecific peptides. These peptides not only recognize tumor cells, but also have the ability to reduce the tumor growth and metastasis [72]. Using 7-mer phage library, cell biopanning was performed on HO-8910 ovarian cancer cell line to obtain a peptide that specifically binds to these cells [73].

Similarly, CSP3 from 12-mer phage library has been reported to have specific binding to SiHa cells (cervical cancer cell lines) [74]. A recent study constructed a drug delivery system based on this peptide, that was composed of chemotherapeutic agent (doxorubicin) conjugated with miRNA 101 and CSP3 peptide. Preliminary results from the study have shown that this system has great specificity towards drug-resistant SiHa cells and enhanced cytotoxicity [75].

\section{Renal Disease}

Cystatin $\mathrm{C}$ is regarded as a crucial 0marker for the evaluation of glomerular filtration rate [76]. A phage display-based nanobody library was used to extract cystatin $\mathrm{C}$ nanobody which was then integrated into titanium dioxide nanotube immunosensor. This sensor resulted in the detection of serum cystatin $\mathrm{C}$ with great sensitivity and specificity [77]. Similarly, kidney injury molecule-1 (KIM1) that is over expressed in damaged tubular cells, ischemic kidney injury and kidney, ovarian and lung cancer conditions, has also been used as antigen for biopanning in order to obtain a peptide that could bind in KIM1-overexprressed cells, especially in renal carcinoma cells [78].

In a recent study, Kim, et al. [79] reported the extraction of agonist of cMet, the transmembrane tyrosine kinase receptor for hepatocyte growth factor, using scFv phage library for antigen biopanning. The antibody had high affinity for cMet and mediated cell migration and proliferation, thereby alleviating kidney fibrosis. The effects were seen by the reduction in the expression of $\alpha \mathrm{SMA}$ (alpha smooth muscle actin), fibronectin and Bax-2 (Bcl-2 associated x protein) while, increasing the expression of Bcl-2 (B-cell lymphoma) and phospho-cMet proteins.

\section{Other therapeutic application}

Phage display has also been exploited for the discovery of snake anti-venom peptides. A study has shown that peptides against Phospholipase $\mathrm{A}_{2}\left(\mathrm{PLA}_{2}\right)$ inhibits PLA $\mathrm{A}_{2}$ activity of the venom of western cottonmouth [80].

A recent study has reported the use of phage display method to produce vaccine against systemic candidiasis as shown in figure 4 .

Nielsen, et al. [81] produced ${ }^{68}$ Ga-labelled cyclic and two linear dodecapeptides for positron emission tomography (PET) scan for the detection of Staphylococcus aureus.

\section{Conclusion and future aspect}

Up to 80 monoclonal antibodies, extracted from phage display technology have entered clinical trial stages and 7 antibodies are approved products. Lately, it has been considered as a gold-standard for the isolation of monoclonal antibodies due to its robust nature and high stability. Phages can bear harsh environmental conditions such as exposure to ultraviolent radiation, extreme temperature and $\mathrm{pH}$ and proteolytic enzymes [82]. In the field of medicine, this technology has been extensively used for the detection of biomarkers, drug delivery and analyzing molecular interactions. To the date, the method is performed in several research laboratory, focusing on clinical researches. However, among some of the limitations of the technique; the requirement of the library and the discovery of only the fraction of molecule (example: scFv or Fab) are the most cumbersome ones [82].

Nonetheless, the development of this technique, in the field of biotechnology and immunology, has made several investigations easier and has also allowed scientist and researches to come up to the better conclusions.

\section{Conflict of interest}


The authors deny any kind of conflict of interest.

\section{Acknowledgement}

None

\section{Funding information}

None

\section{References}

1. Frenzel A, Schirrmann T, Hust M. Phage display-derived human antibodies in clinical development and therapy. MAbs 2016;8 (7):1177-94 doi: 10.1080/19420862.2016.1212149[published Online First: Epub Date]|.

2. Wang Y, Gao S, Lv J, Lin Y, Zhou L, Han L. Phage Display Technology and its Applications in Cancer Immunotherapy. Anti-cancer agents in medicinal chemistry 2019;19 (2):229-35 doi:10.2174/1871520618666181029140814[published Online First: Epub Date]|.

3. Aghebati-Maleki L, Bakhshinejad B, Baradaran B, et al. Phage display as a promising approach for vaccine development. Journal of biomedical science 2016;23 (1):66-66 doi: 10.1186/s12929-016-0285-9[published Online First: Epub Date]|.

4. Peltomaa R, Benito-Peña E, Barderas R, Moreno-Bondi MC. Phage Display in the Quest for New Selective Recognition Elements for Biosensors. ACS Omega 2019;4 (7):11569-80 doi: 10.1021/acsomega.9b01206[published Online First: Epub Date]|.

5. Barderas R, Benito-Pena E. The 2018 Nobel Prize in Chemistry: phage display of peptides and antibodies. Analytical and bioanalytical chemistry 2019;411 (12):2475-79 doi: 10.1007/s00216-019-01714-4[published Online First: Epub Date]|.

6. Bakhshinejad B, Zade HM, Shekarabi HS, Neman S. Phage display biopanning and isolation of targetunrelated peptides: in search of nonspecific binders hidden in a combinatorial library. Amino acids 2016;48 (12):2699-716 doi: 10.1007/s00726-016-2329-6[published Online First: Epub Date]|.

7. Kumar A, Singh A, Ekavali. A review on Alzheimer's disease pathophysiology and its management: an update. Pharmacological Reports 2015;67 (2):195-203 doi: https://doi.org/10.1016/j.pharep.2014.09.004[published Online First: Epub Date]|.

8. van Groen T, Wiesehan K, Funke SA, Kadish I, Nagel-Steger L, Willbold D. Reduction of Alzheimer's Disease Amyloid Plaque Load in Transgenic Mice by D3, a D-Enantiomeric Peptide Identified by Mirror Image Phage Display. ChemMedChem 2008;3 (12):1848-52 doi: 10.1002/cmdc.200800273[published Online First: Epub Date]|.

9. Dammers C, Yolcu D, Kukuk L, et al. Selection and Characterization of Tau Binding ?-Enantiomeric Peptides with Potential for Therapy of Alzheimer Disease. PLOS ONE 2016;11 (12):e0167432 doi: 10.1371/journal.pone.0167432[published Online First: Epub Date]|.

10. Rudolph S, Klein AN, Tusche M, et al. Competitive Mirror Image Phage Display Derived Peptide Modulates Amyloid Beta Aggregation and Toxicity. PLOS ONE 2016;11 (2):e0147470 doi: 10.1371/journal.pone.0147470[published Online First: Epub Date]|.

11. Read J, Suphioglu C. Identification of a BACE1 Binding Peptide Candidate for the Prevention of Amyloid Beta in Alzheimer's Disease. Cellular physiology and biochemistry: international journal of experimental cellular physiology, biochemistry, and pharmacology 2019;53 (2):413-28

12. Cai C, Dai X, Zhu Y, et al. A specific RAGE-binding peptide biopanning from phage display random peptide library that ameliorates symptoms in amyloid $\beta$ peptide-mediated neuronal disorder. Applied Microbiology and Biotechnology 2016;100 (2):825-35 doi: 10.1007/s00253-015-7001-7[published Online First: Epub Date]|. 
13. Rauth S, Hinz D, Börger M, et al. High-affinity Anticalins with aggregation-blocking activity directed against the Alzheimer $\beta$-amyloid peptide. Biochemical Journal 2016;473 (11):1563-78 doi: 10.1042/bcj20160114[published Online First: Epub Date]|.

14. Munke A, Persson J, Weiffert T, et al. Phage display and kinetic selection of antibodies that specifically inhibit amyloid self-replication. Proceedings of the National Academy of Sciences 2017;114:201700407 doi: 10.1073/pnas.1700407114[published Online First: Epub Date]|.

15. Chen J, Huang Y, Zhu C, et al. Early detection of Alzheimer's disease by peptides from phage display screening. Brain Res 2019;1721 :146306 doi: 10.1016/j.brainres.2019.146306[published Online First: Epub Date]|.

16. San Segundo-Acosta P, Montero-Calle A, Garranzo-Asensio M, et al. ANALYSIS OF THE HUMORAL RESPONSE IN ALZHEIMER\&\#x2019;S DISEASE USING THE HIGH-THROUGHPUT SCREENING COMBINATION OF T7 PHAGE LIBRARIES AND PROTEIN MICROARRAYS. Alzheimer's \& Dementia: The Journal of the Alzheimer's Association 2017;13 (7):P1034 doi: 10.1016/j.jalz.2017.06.1458[published Online First: Epub Date]|.

17. San Segundo-Acosta P, Montero-Calle A, Fuentes M, Rábano A, Villalba M, Barderas R. Identification of Alzheimer's Disease Autoantibodies and Their Target Biomarkers by Phage Microarrays. Journal of Proteome Research 2019;18 (7):2940-53 doi: 10.1021/acs.jproteome.9b00258[published Online First: Epub Date]|.

18. Mann AP, Scodeller P, Hussain S, et al. Identification of a peptide recognizing cerebrovascular changes in mouse models of Alzheimer's disease. Nature Communications 2017;8 (1):1403 doi: 10.1038/s41467-01701096-0[published Online First: Epub Date]|.

19. Tai C-Y, Ma H-T, Huang S-C, et al. IDENTIFICATION OF SYNAPTIC TAU ANTIBODIES IN ALZHEIMER'S DISEASE AND RELATED TAUOPATHIES. Alzheimer's \& Dementia: The Journal of the Alzheimer's Association 2018;14 (7):P1440 doi: 10.1016/j.jalz.2018.06.2421[published Online First: Epub Date]|.

20. Turner MD. The identification of TNFR5 as a therapeutic target in diabetes. Expert Opinion on Therapeutic Targets 2017;21 (4):349-51 doi: 10.1080/14728222.2017.1297426[published Online First: Epub Date]|.

21. Ndisang JF, Vannacci A, Rastogi S. Insulin Resistance, Type 1 and Type 2 Diabetes, and Related Complications 2017. J Diabetes Res 2017;2017 :1478294-94 doi: 10.1155/2017/1478294[published Online First: Epub Date]|.

22. King R, Tiede C, Simmons K, Fishwick C, Tomlinson D, Ajjan R. Inhibition of complement C3 and fibrinogen interaction: a potential novel therapeutic target to reduce cardiovascular disease in diabetes. The Lancet 2015;385 :S57 doi: https://doi.org/10.1016/S0140-6736(15)60372-5[published Online First: Epub Date]|.

23. Tucker DF, Sullivan JT, Mattia KA, et al. Isolation of state-dependent monoclonal antibodies against the 12-transmembrane domain glucose transporter 4 using virus-like particles. Proc Natl Acad Sci U S A 2018;115 (22):E4990-e99 doi: 10.1073/pnas.1716788115[published Online First: Epub Date]|.

24. Ngoh Y-Y, Lim TS, Gan C-Y. Screening and identification of five peptides from pinto bean with inhibitory activities against $\alpha$-amylase using phage display technique. Enzyme and Microbial Technology 2016;89:76-84 doi: https://doi.org/10.1016/j.enzmictec.2016.04.001[published Online First: Epub Date]|.

25. Tenspolde M, Zimmermann K, Weber LC, et al. Regulatory T cells engineered with a novel insulinspecific chimeric antigen receptor as a candidate immunotherapy for type 1 diabetes. Journal of Autoimmunity 2019;103 :102289 doi: https://doi.org/10.1016/j.jaut.2019.05.017[published Online First: Epub Date]|.

26. Kim D, Jeon H, Ahn S, Choi WI, Kim S, Jon S. An approach for half-life extension and activity preservation of an anti-diabetic peptide drug based on genetic fusion with an albumin-binding aptide. Journal 
of Controlled Release 2017;256 :114-20 doi: https://doi.org/10.1016/j.jconrel.2017.04.036[published Online First: Epub Date]|.

27. Demartis A, Lahm A, Tomei L, et al. Polypharmacy through Phage Display: Selection of Glucagon and GLP-1 Receptor Co-agonists from a Phage-Displayed Peptide Library. Scientific Reports 2018;8 (1):585 doi: 10.1038/s41598-017-18494-5[published Online First: Epub Date]|.

28. Gomes KFB, Semzezem C, Batista R, et al. Importance of Zinc Transporter 8 Autoantibody in the Diagnosis of Type 1 Diabetes in Latin Americans. Scientific Reports 2017;7 (1):207 doi: 10.1038/s41598017-00307-4[published Online First: Epub Date]|.

29. Wu Q, Wang X, Gu Y, et al. Screening and identification of human ZnT8-specific single-chain variable fragment ( $\mathrm{scFv}$ ) from type 1 diabetes phage display library. Science China Life Sciences 2016;59 (7):686-93 doi: 10.1007/s11427-016-5077-7[published Online First: Epub Date]|.

30. Inoue H, Shintani N, Sakurai Y, et al. PACAP Inhibits $\beta$-cell Mass Expansion in a Mouse Model of Type II Diabetes: Persistent Suppressive Effects on Islet Density. Front Endocrinol (Lausanne) 2013;4 (27) doi: 10.3389/fendo.2013.00027[published Online First: Epub Date]|.

31. Ma Y, Fang S, Zhao S, et al. A recombinant slow-release PACAP-derived peptide alleviates diabetes by promoting both insulin secretion and actions. Biomaterials 2015;51 :80-90 doi: 10.1016/j.biomaterials.2015.01.064[published Online First: Epub Date]|.

32. Bene J, Hadzsiev K, Melegh B. Role of carnitine and its derivatives in the development and management of type 2 diabetes. Nutrition \& Diabetes 2018;8 (1):8 doi: 10.1038/s41387-018-0017-1[published Online First: Epub Date]|.

33. Abou El-Magd RM, Vozza NF, Tuszynski JA, Wishart DS. Isolation of soluble scFv antibody fragments specific for small biomarker molecule, L-Carnitine, using phage display. J Immunol Methods 2016;428 :9-19 doi: 10.1016/j.jim.2015.11.006[published Online First: Epub Date]|.

34. Fahimi F, Sarhaddi S, Fouladi M, et al. Phage display-derived antibody fragments against conserved regions of VacA toxin of Helicobacter pylori. Applied Microbiology and Biotechnology 2018;102 (16):6899913 doi: 10.1007/s00253-018-9068-4[published Online First: Epub Date]|.

35. Xiong Y, Yang Z, Zhang J, Li J, Chen P, Xiang Y. Panning using a phage-displayed random peptide library to identify peptides that antagonize the Helicobacter pylori ArsS acid-sensing domain. Microbial Pathogenesis 2019;135 :103614 doi: https://doi.org/10.1016/j.micpath.2019.103614[published Online First: Epub Date]|.

36. Facchin S, Digiglio L, D'Incà R, et al. Discrimination between ulcerative colitis and Crohn's disease using phage display identified peptides and virus-mimicking synthetic nanoparticles. Nanomedicine: Nanotechnology, Biology and Medicine 2017;13 (6):2027-36 doi: https://doi.org/10.1016/j.nano.2017.04.007[published Online First: Epub Date]|.

37. Cardona-Correa A, Rios-Velazquez C. Profiling lethal factor interacting proteins from human stomach using T7 phage display screening. Mol Med Rep 2016;13 (5):3797-804 doi: 10.3892/mmr.2016.5031[published Online First: Epub Date]|.

38. Park JP, Cropek DM, Banta S. High affinity peptides for the recognition of the heart disease biomarker troponin I identified using phage display. Biotechnol Bioeng 2010;105 (4):678-86 doi: 10.1002/bit.22597[published Online First: Epub Date]|.

39. Cooksley-Decasper S, Reiser H, Thommen DS, et al. Antibody phage display assisted identification of junction plakoglobin as a potential biomarker for atherosclerosis. PloS one 2012;7 (10):e47985-e85 doi: 10.1371/journal.pone.0047985[published Online First: Epub Date]|. 
40. Hemadou A, Laroche-Traineau J, Antoine S, et al. An innovative flow cytometry method to screen human scFv-phages selected by in vivo phage-display in an animal model of atherosclerosis. Scientific Reports 2018;8 (1):15016 doi: 10.1038/s41598-018-33382-2[published Online First: Epub Date]|.

41. Jacobin-Valat MJ, Hemadou A, Fontayne A, et al. In Vivo Human Scfv Phage Display Assisted Identification Of Galectin-3 As A New Biomarker For Atherosclerosis. Atherosclerosis 2019;287 :e166 doi: 10.1016/j.atherosclerosis.2019.06.502[published Online First: Epub Date]|.

42. Unbiased Screening of Kawasaki Disease Sera for Viral Antigen Exposure. Open forum infectious diseases; 2017. Oxford University Press.

43. Negi P, Lövgren J, Malmi P, et al. Identification and analysis of anti-HDL scFv-antibodies obtained from phage display based synthetic antibody library. Clinical Biochemistry 2016;49 (6):472-79 doi: https://doi.org/10.1016/j.clinbiochem.2015.11.020[published Online First: Epub Date]|.

44. Saw PE, Song EW. Phage display screening of therapeutic peptide for cancer targeting and therapy. Protein \& cell 2019;10 (11):787-807 doi: 10.1007/s13238-019-0639-7[published Online First: Epub Date]|.

45. Choi J-S, Joo SH. Recent Trends in Cyclic Peptides as Therapeutic Agents and Biochemical Tools. Biomolecules \& therapeutics 2020;28 (1):18

46. Yang H, Park H, Lee YJ, et al. Development of Human Monoclonal Antibody for Claudin-3 Overexpressing Carcinoma Targeting. Biomolecules 2020;10 (1):51

47. Shukla GS, Krag DN, Peletskaya EN, et al. Intravenous infusion of phage-displayed antibody library in human cancer patients: enrichment and cancer-specificity of tumor-homing phage-antibodies. Cancer Immunol Immunother 2013;62 (8):1397-410 doi: 10.1007/s00262-013-1443-5[published Online First: Epub Date]|.

48. Ten Haaf A, Pscherer S, Fries K, Barth S, Gattenlohner S, Tur MK. Phage display-based on-slide selection of tumor-specific antibodies on formalin-fixed paraffin-embedded human tissue biopsies. Immunology letters 2015;166 (2):65-78 doi: 10.1016/j.imlet.2015.05.013[published Online First: Epub Date]|.

49. Carneiro AP, Reis CF, Morari EC, et al. A putative OTU domain-containing protein 1 deubiquitinating enzyme is differentially expressed in thyroid cancer and identifies less-aggressive tumours. Br J Cancer 2014;111 (3):551-58 doi: 10.1038/bjc.2014.331[published Online First: Epub Date]|.

50. Liu Q, Pang H, Hu X, et al. Construction of human single-chain variable fragment antibodies of medullary thyroid carcinoma and single photon emission computed tomography/computed tomography imaging in tumor-bearing nude mice. Oncology reports 2016;35 (1):171-8 doi: 10.3892/or.2015.4345[published Online First: Epub Date]|.

51. Jin W, Qin B, Chen Z, Liu H, Barve A, Cheng K. Discovery of PSMA-specific peptide ligands for targeted drug delivery. Int J Pharm 2016;513 (1-2):138-47 doi: 10.1016/j.ijpharm.2016.08.048[published Online First: Epub Date]|.

52. Wada A, Terashima T, Kageyama S, et al. Efficient Prostate Cancer Therapy with Tissue-Specific Homing Peptides Identified by Advanced Phage Display Technology. Mol Ther Oncolytics 2019;12 :138-46 doi: 10.1016/j.omto.2019.01.001[published Online First: Epub Date]|.

53. Fitting J, Blume T, Ten Haaf A, et al. Phage display-based generation of novel internalizing antibody fragments for immunotoxin-based treatment of acute myeloid leukemia. MAbs 2015;7 (2):390-402 doi: 10.1080/19420862.2015.1007818[published Online First: Epub Date]|.

54. Muchima K, Todaka T, Shinchi H, et al. Development of sugar chain-binding single-chain variable fragment antibody to adult T-cell leukemia cells using glyco-nanotechnology and phage display method. The Journal of Biochemistry 2018;163 (4):281-91 doi: 10.1093/jb/mvy005[published Online First: Epub Date]|.

55. FITC-Labelled Clone from Phage Display for Direct Detection of Leukemia Cells in Blood; 2019; Cham. Springer International Publishing. 
56. Ljungars A, Mårtensson L, Mattsson J, et al. A platform for phenotypic discovery of therapeutic antibodies and targets applied on Chronic Lymphocytic Leukemia. npj Precision Oncology 2018;2 (1):18 doi: 10.1038/s41698-018-0061-2[published Online First: Epub Date]|.

57. Larsen SA, Meldgaard T, Fridriksdottir AJ, et al. Raising an Antibody Specific to Breast Cancer Subpopulations Using Phage Display on Tissue Sections. Cancer genomics \& proteomics 2016;13 (1):21-30

"58. Sørensen KMJ, Meldgaard T, Melchjorsen CJ, et al. Upregulation of Mrps18a in breast cancer identified by selecting phage antibody libraries on breast tissue sections. BMC Cancer 2017;17 (1):19 doi: 10.1186/s12885-016-2987-5[published Online First: Epub Date]|.

59. Mendes TFS, Kluskens LD, Rodrigues LR. Triple Negative Breast Cancer: Nanosolutions for a Big Challenge. Advanced Science 2015;2 (11):1500053 doi: 10.1002/advs.201500053[published Online First: Epub Date]|.

60. Liu F, Qi CL, Kong M, Liu TT, Li L, Li BJ. Screening specific polypeptides of breast cancer stem cells from a phage display random peptide library. Oncology letters 2016;12 (6):4727-31

61. Galbiati E, Gambini L, Civitarese V, et al. Blind targeting in action: From phage display to breast cancer cell targeting with peptide-gold nanoconjugates. Pharmacological Research 2016;111 :155-62 doi: https://doi.org/10.1016/j.phrs.2016.06.007[published Online First: Epub Date]|.

62. Jones KM, Karanam B, Jones-Triche J, et al. Phage Ligands for Identification of MesenchymalLike Breast Cancer Cells and Cancer-Associated Fibroblasts. Front Oncol 2018;8 (625) doi: 10.3389/fonc.2018.00625[published Online First: Epub Date]|.

63. Hou L, Zhu D, Liang Y, et al. Identification of a specific peptide binding to colon cancer cells from a phage-displayed peptide library. British Journal Of Cancer 2017;118 :79 doi: 10.1038/bjc.2017.366

https://www.nature.com/articles/bjc2017366\#supplementary-information[published Online First: Epub Date]|.

64. Ferreira D, Silva AP, Nobrega FL, et al. Rational Identification of a Colorectal Cancer Targeting Peptide through Phage Display. Scientific Reports 2019;9 (1):3958 doi: 10.1038/s41598-019-40562-1[published Online First: Epub Date]|.

65. He X-q, Guan J, Liu F, Li J, He M-r. Identification of the sAPRIL Binding Peptide and Its Growth Inhibition Effects in the Colorectal Cancer Cells. PLOS ONE 2015;10 (3):e0120564 doi: 10.1371/journal.pone.0120564[published Online First: Epub Date]|.

66. Sahin D, Taflan SO, Yartas G, Ashktorab H, Smoot DT. Screening and Identification of Peptides Specifically Targeted to Gastric Cancer Cells from a Phage Display Peptide Library. Asian Pacific journal of cancer prevention : APJCP 2018;19 (4):927-32 doi: 10.22034/apjcp.2018.19.4.927[published Online First: Epub Date]|.

67. Wang JJ, Liu Y, Zheng Y, et al. Screening peptides binding specifically to colorectal cancer cells from a phage random peptide library. Asian Pacific journal of cancer prevention : APJCP 2012;13 (1):377-81 doi: 10.7314/apjcp.2012.13.1.377[published Online First: Epub Date]|.

68. Ma C, Li C, Jiang D, et al. Screening of a specific peptide binding to esophageal squamous carcinoma cells from phage displayed peptide library. Mol Cell Probes 2015;29 (3):182-9 doi: 10.1016/j.mcp.2015.04.001[published Online First: Epub Date]|.

69. Yang X, Zhang F, Luo J, et al. A new non-muscle-invasive bladder tumor-homing peptide identified by phage display in vivo. Oncology reports 2016;36 (1):79-89

70. Guo Y, Ma C, Li C, et al. Screening and identification of a specific peptide binding to hepatocellular carcinoma cells from a phage display peptide library. Journal of peptide science : an official publication of the European Peptide Society 2014;20 (3):196-202 doi: 10.1002/psc.2599[published Online First: Epub Date]|. 
71. Wang J, Tan X, Guo Q, et al. FGF9 inhibition by a novel binding peptide has efficacy in gastric and bladder cancer per se and reverses resistance to cisplatin. Pharmacological Research 2020;152:104575 doi: https://doi.org/10.1016/j.phrs.2019.104575[published Online First: Epub Date]|.

72. Zhou C, Kang J, Wang X, Wei W, Jiang W. Phage display screening identifies a novel peptide to suppress ovarian cancer cells in vitro and in vivo in mouse models. BMC Cancer 2015;15 (1):889 doi: 10.1186/s12885015-1891-8[published Online First: Epub Date]|.

73. Wang $\mathrm{L}, \mathrm{Hu} \mathrm{Y}, \mathrm{Li} \mathrm{W}$, et al. Identification of a peptide specifically targeting ovarian cancer by the screening of a phage display peptide library. Oncology letters 2016;11 (6):4022-26 doi: 10.3892/ol.2016.4549[published Online First: Epub Date]|.

74. Li C, Gao N, Xue Q, et al. Screening and identification of a specific peptide binding to cervical cancer cells from a phage-displayed peptide library. Biotechnology letters 2017;39 (10):1463-69 doi: 10.1007/s10529017-2381-7[published Online First: Epub Date]|.

75. Xiao L, Ma N, He H, et al. Development of a novel drug targeting delivery system for cervical cancer therapy. Nanotechnology 2019;30 (7):075604 doi: 10.1088/1361-6528/aaf3f8[published Online First: Epub Date]|.

76. Grubb A. Cystatin C is Indispensable for Evaluation of Kidney Disease. EJIFCC 2017;28 (4):268-76

77. Mi L, Wang P, Yan J, et al. A novel photoelectrochemical immunosensor by integration of nanobody and TiO2 nanotubes for sensitive detection of serum cystatin C. Analytica Chimica Acta 2016;902 :107-14 doi: https://doi.org/10.1016/j.aca.2015.11.007[published Online First: Epub Date]|.

78. Yoon J-W, Lee S-w, Haque ME, et al. Abstract 1147: A phage display identified peptide selectively binds to kidney injury molecule-1(KIM-1) and detects KIM-1-overexpressing tumors $<$ em $>$ in vivo $</$ em $>$. Cancer research 2019;79 (13 Supplement):1147-47 doi: 10.1158/1538-7445.am2019-1147[published Online First: Epub Date]|.

79. Kim YC, Lee J, An JN, et al. Renoprotective effects of a novel cMet agonistic antibody on kidney fibrosis. Scientific Reports 2019;9 (1):13495 doi: 10.1038/s41598-019-49756-z[published Online First: Epub Date]|.

80. Titus JK, Kay MK, Glaser CJJ. Application of phage display for the development of a novel inhibitor of PLA2 activity in Western cottonmouth venom. J Venom Res 2017;8 :19-24

81. Nielsen KM, Kyneb MH, Alstrup AKO, et al. 68Ga-labeled phage-display selected peptides as tracers for positron emission tomography imaging of Staphylococcus aureus biofilm-associated infections: Selection, radiolabelling and preliminary biological evaluation. Nuclear Medicine and Biology 2016;43 (10):593-605 doi: https://doi.org/10.1016/j.nucmedbio.2016.07.002[published Online First: Epub Date]|.

82. Kumar R, Parray HA, Shrivastava T, Sinha S, Luthra K. Phage display antibody libraries: A robust approach for generation of recombinant human monoclonal antibodies. International Journal of Biological Macromolecules 2019;135:907-18 doi: https://doi.org/10.1016/j.ijbiomac.2019.06.006[published Online First: Epub Date]|. 


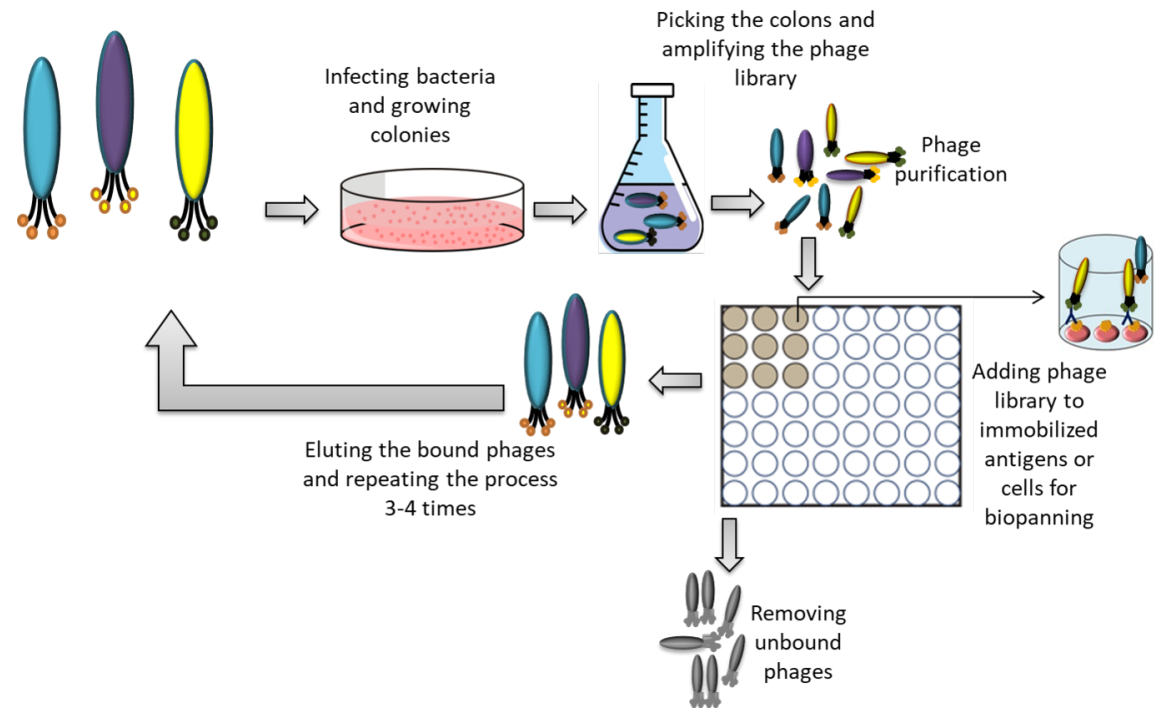

Figure 1 summarizes the basic process of phage display technology.

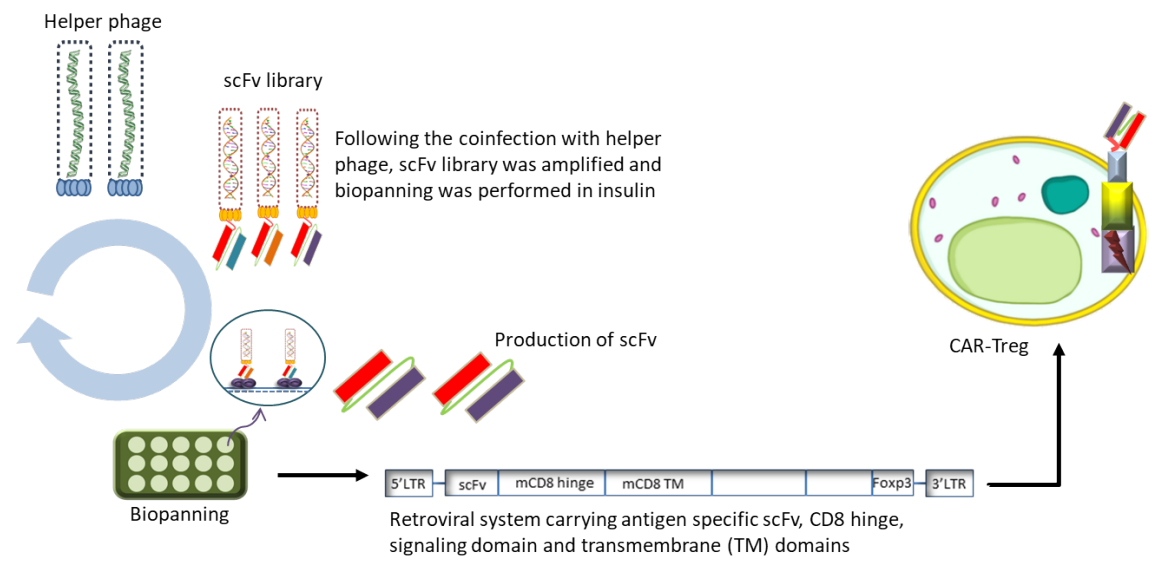

Figure 2 depicts the use of phage display technique to produce insulin specific-chimeric receptors (CAR) expressing T-regulatory cells

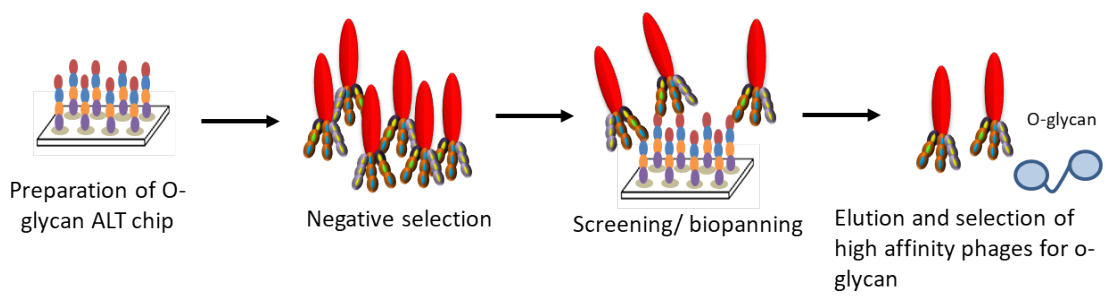

Figure 3 represents the application of phage display method to extract Adult T-cell leukemia-specific scFv, that can specifically bind to sugars expressed on these cells. 


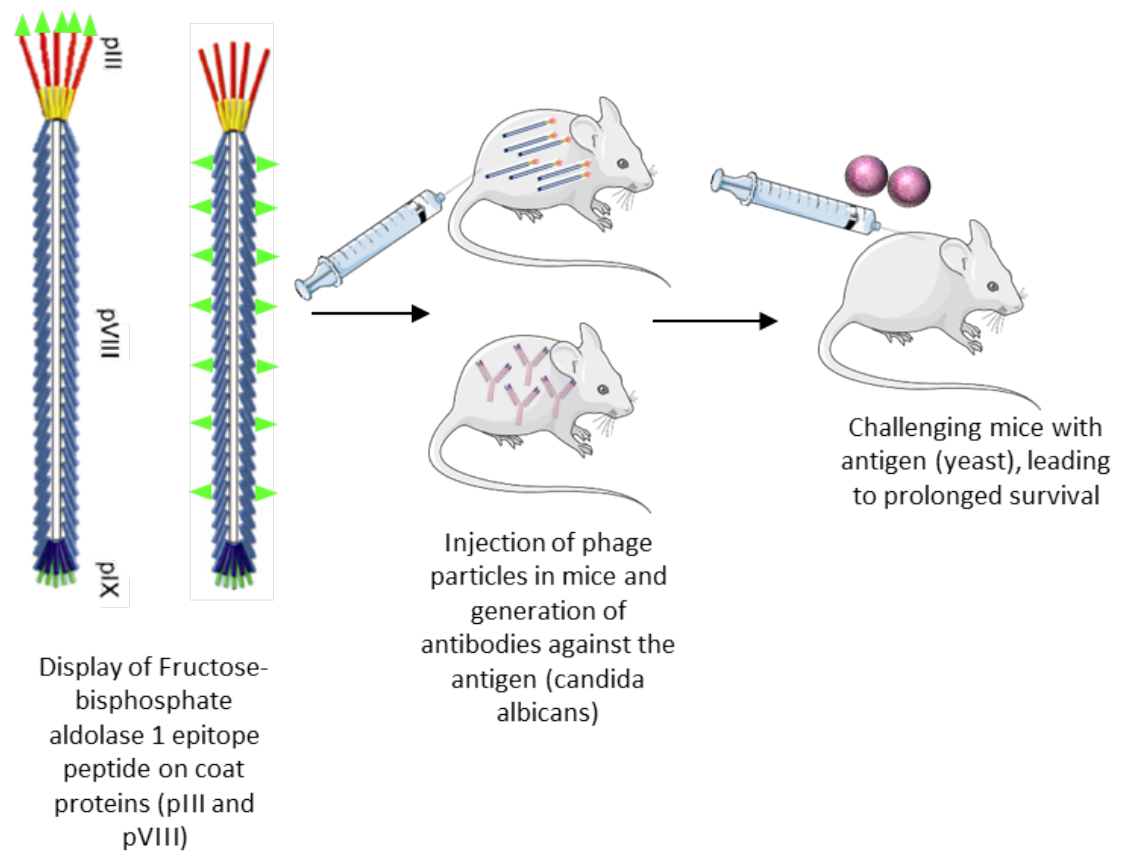

Figure 4 illustrates the development of vaccine against candidiasis using phage display 